\title{
Application of GPS for fisheries
}

TOSHIHARU KAKIHARA ${ }^{1}$

1 Department of Marine Science and Technology, Tokyo University of Fisheries, Minato-ku, Tokyo, 108-8477, Japan (kakky@tokyo-u-fish.ac.jp)

SUMMARY : Selective Availability (SA) in order to degrade the position accuracy of Global Positioning System(GPS), was turned off in May, 2000. This improved new positioning accuracy of GPS is reported. And, the GPS compass for ship heading sensor and a small drifting buoy's monitoring system by using low earth orbit (LEO) communication satellite are introduced as the recent unique applications of GPS for fisheries. The results of the evaluation test used these GPS application instruments are also discussed.

\section{KEY WORDS : GPS, positioning accuracy, GPS compass, ORBCOMM system}

\section{INTRODUCTION}

The Navstar Global Positioning System (GPS) is designed to be a worldwide continuous satellite navigation system. The system is now fully operational after a long developmental period. The system is run and controlled by the United States Department of Defense (DOD). Users can expect three-dimensional positioning, time and velocity measurements available on a 24-hour basis anywhere on earth. The system offers horizontal positions and altitudes at an update rate typically less than one second.

GPS is now one of the primary navigation tools on fishing boats and merchant ships for both offshore and coastal navigation. The Standard Positioning Service (SPS) is available to civil use and the horizontal positioning accuracy had been intentionally degraded for the purpose of the U.S. national defense. But this policy that is called Selective Availability (SA), was turned off without previous announcement in 2000 .

In this paper, the recent GPS positioning accuracy, the principle and heading performance of GPS compass, and finally the concept and current situation of the drifting buoy monitoring system are introduced and discussed.

\section{MATERIALS AND METHODS}

The observation of positioning accuracy of GPS after SA termination was made continuously at the fixed land point in Tokyo in 2000. And, the ship heading indication performance of twin antenna type GPS compass are discussed with referring the result of evaluation experiment conducted on board a small fishing boat. The position monitoring test of small drifting buoy with a built-in GPS by using ORBCOMM system that is a kind of telemetry system through LEO satellite, are carried out at sea and during the training ship's a round-Japan cruise in 2001

\section{Termination of GPS SA}

GPS that is a satellite-based navigation system, is managed by the United State. GPS user receiver measures the pseudo range between individual satellite and the user to determine ship's position. GPS is operated using 24 satellites in 6 orbital planes of 12-hours period. GPS provides threedimensional position. Therefore, in order to compute the position and time, more than 4 satellites are needed. The positioning is available for 24-hours continuously, all weather and anywhere on the Earth except for inside of

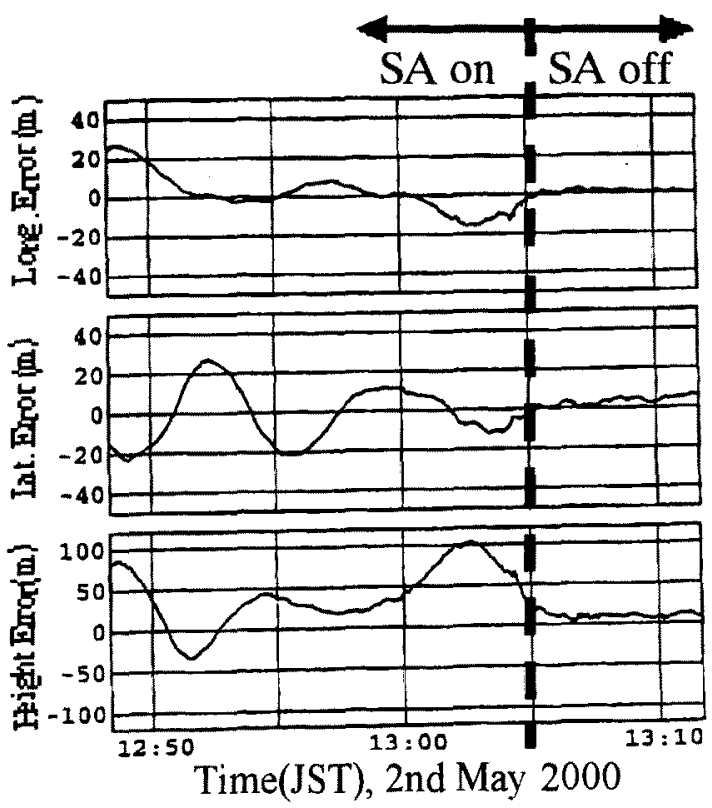

Fig.1 Position errors change with time 

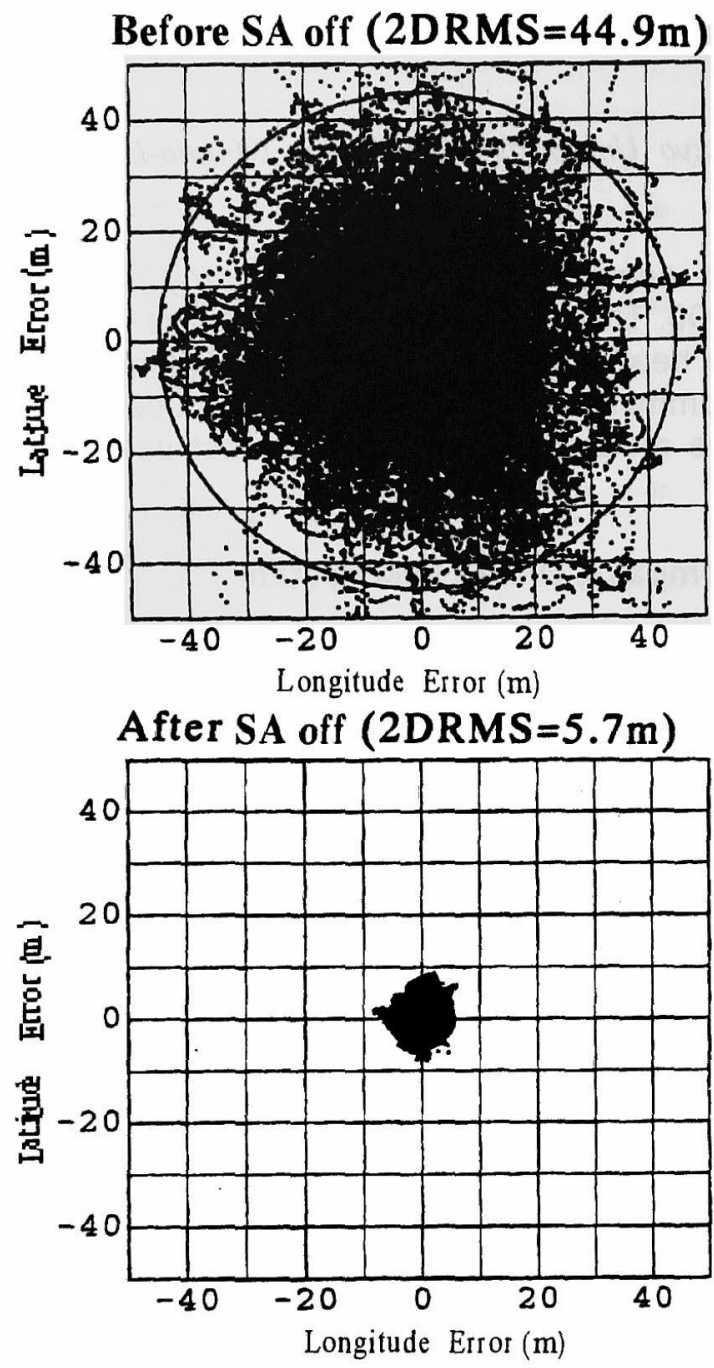

Fig.2 Error distribution before and after SA off

building or tunnel.

There are two kinds of positioning services provided by USA. One is Standard Positioning Service for civil use, short form is SPS and the other is Precise Positioning Service, PPS for military use. The SPS had been intentionally degraded positioning accuracy to $100 \mathrm{~m}$ for the purpose of national defense of United State. This degradation policy was called Selective Availability, that is SA. But this SA was turned off suddenly. The U.S. President Bill Clinton announced the following statement about the termination of SA in May $1^{\text {st }}, 2000$. "The decision to discontinue Selective Availability is the latest measure in an ongoing effort to make GPS more responsive to civil and commercial users worldwide. This increase in accuracy will allow new GPS applications to emerge and continue to enhance the lives of people around the world." By termination of SA, the positioning accuracy increases from a hundred meters to 1020 meters.

This improved SPS accuracy observed in Tokyo is shown in this section. Fig. 1 shows the position errors change with time observed in Tokyo during just before and after the SA termination. The broken line in figure indicates the time of SA turned off. The time was at thirteen o'clock past 5 in Japan standard time, on $2^{\text {nd }}$ May 2000. Upper graph is longitude error in meter, middle is latitude and bottom is height. Each error changes irregularly and largely by the affect of SA before termination. But, after termination, the errors are very small and stable.

Fig. 2 shows the horizontal position error distribution before SA off and after SA off observed in Tokyo too. In case of SA on, the scattering of error is large, and the two times distance root mean square, that is 2DRMS, was $44.9 \mathrm{~m}$. 2DRMS means the radius of $95 \%$ probability error circle. On the other hand, the position errors concentrate around the graph origin that is a geodetic correct position at the observation site and 2DRMS was only $5.7 \mathrm{~m}$ in case of SA off. This improved accuracy by SA off will be very useful for safety ship navigation and fisheries.

\section{GPS Compass}

Own ship's heading can be determined by decoding the phase data in the GPS carrier frequency $(1575.42 \mathrm{MHz})$. Although a number of antenna is different by marine navigational instrument maker, from 2 to 4 GPS antennas are used for heading calculation.

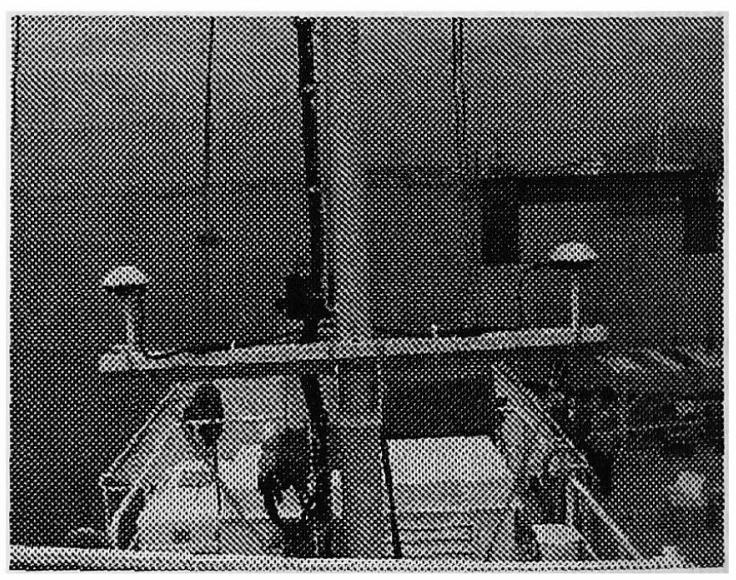

Fig.3 Twin antenna type GPS compass

In principal in the simplest twin antenna type, a pair of antennas, each connected with an 
associated GPS receiver, are installed along, or at a right angle to the ship's fore-aft line. Fig. 3 shows the twin antenna of GPS compass installed at a small training boat HIYODORI in order to observe the heading indication performance in Tokyo. By using the GPS kinematic technology in geographical survey, the vector (range and orientation) between both antennas, i.e., heading of own ship relative to north is calculated.

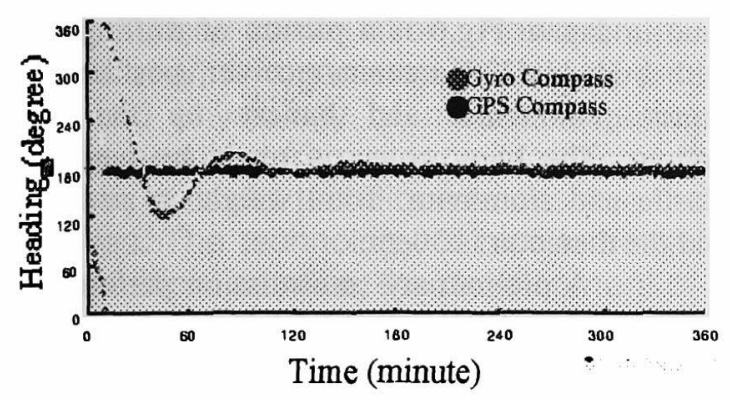

Fig.4 Heading change Comparison between Gyro and GPS

The heading accuracy is said that it is kept within \pm 1 degree and the resolution is 0.1 degree. This accuracy is the almost same with gyro compass. The compass performance is not affected by ship's speed, latitude, geomagnetism. Settling time of is shorter compared to the gyrocompass, it takes $3 \sim 10$ minutes for initialization. GPS compass system has also a full function of GPS, and the system can output the GPS three dimensional position (latitude, longitude and height), speed over the ground. The follow-up rate against true heading is $\mathbf{2 5}$ degrees per second. GPS compass heading data is also available for Radar/ARPA, video-plotter and Electric Chart System.
Fig. 4 indicates the change of gyro and GPS compass heading with time in static condition. Both Circles in figure shows gyro and GPS compass headings respectively. In this experiment, both powers of compasses were switched on at the same time. From the figure, it took about 2hours in gyro compass until the heading became stable. On the other hand, GPS compass initialization time was only 10 minutes. This shorter setting time is a merit of GPS compass though both heading data after stability were almost same.

\section{Satellite Monitoring System (ORBCOMM System)}

ORBCOMM system is the commercial global wireless data and messaging communications system from space. The system uses 36 LowEarth-Orbit (LEO) communication satellites on 6 orbits to provide worldwide geographic coverage.

By this constellation, user can communicate with satellite 24 hours at anyplace on earth. The height from earth is about $800 \mathrm{~km}$ and the round period is 90 minutes. The two main components of the ORBCOMM system are the space segment and the ground segment including system control center and subscriber communicators (user transmitter).

When a drifting buoy with built-in the ORBCOMM transmitter connecting to GPS receiver is used for the position monitoring of fishing boat and fishing gear, the track of buoy

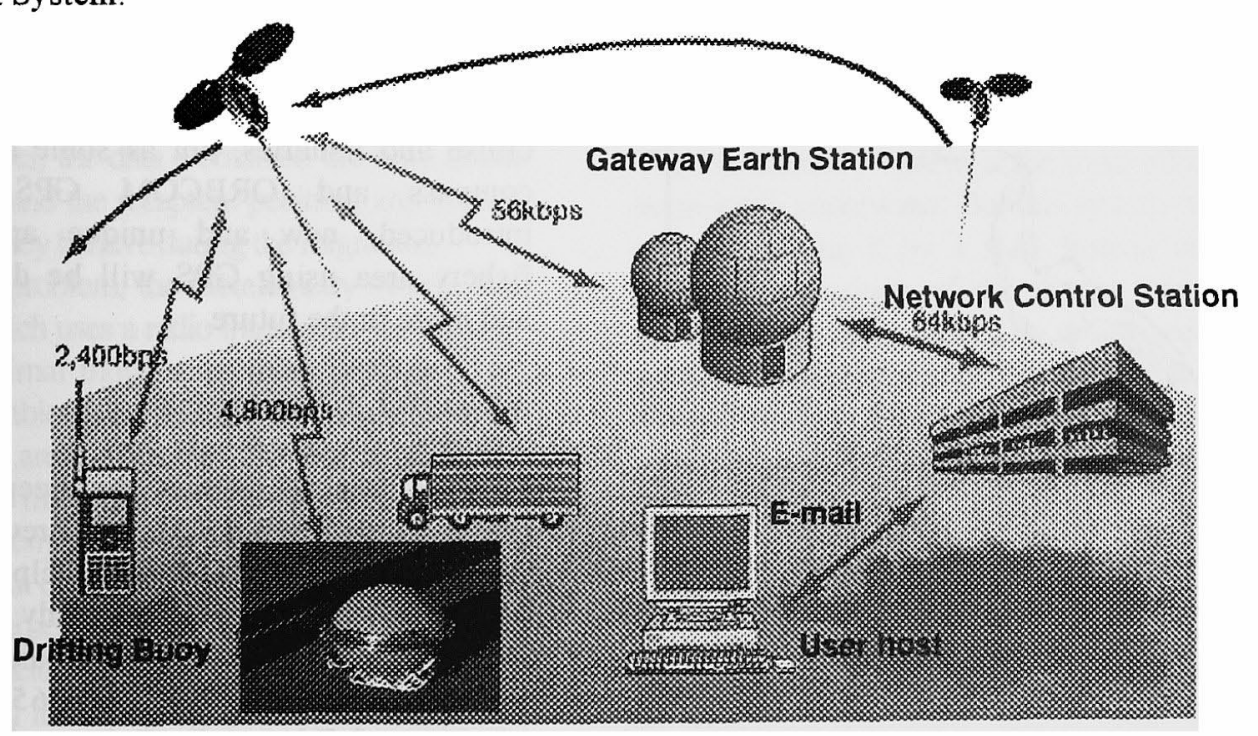

Fig.5 Concept of ORBCOMM network 


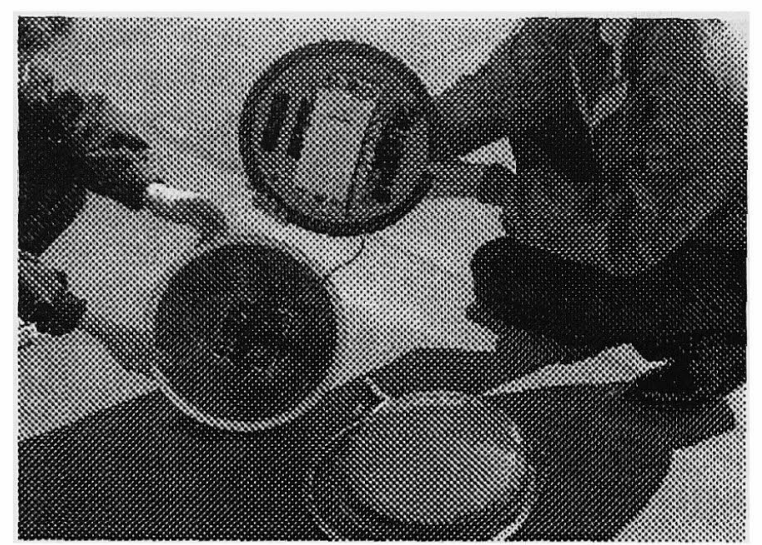

Fig.6 Inside of drifting buoy with built-in GPS and ORBCOMM transmitter

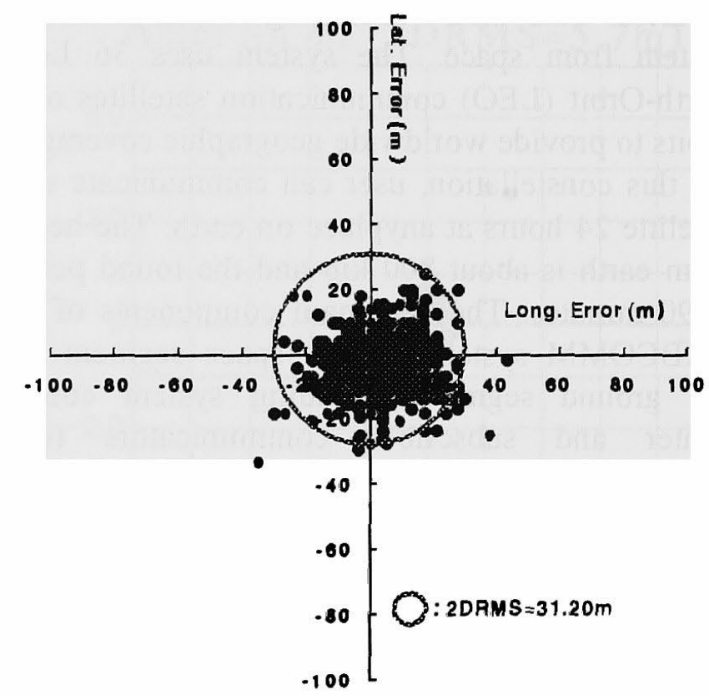

Fig.7 Drifting buoy position error observed at sea

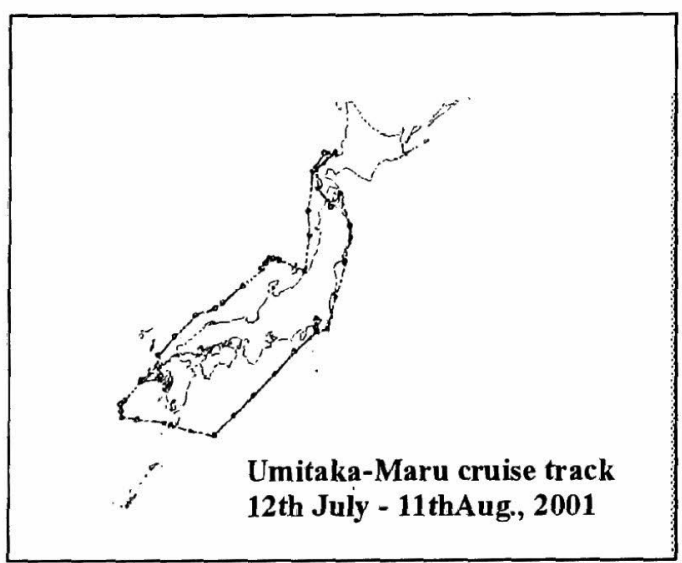

Fig.8 Ship's track monitored by ORBCOMM system during a round-Japan cruise

being at any sea area can be monitored in real time at an office or a laboratory of user through e- mail via the $L E O$ satellite.

Fig. 5 shows ORBCOM network. The data measured by mobile transmitter, truck and drifting buoy with built-in GPS are transmitted to the ORBCOMM satellite. Next, the stored data in the satellite are sent to Gateway Earth Station. And, finally, the data are distributed to user's PC by e-mail via Network control center. For example, when the buoy is drifting on central Pacific, user can know the buoy location in real time in Japan. Fig. 6 is a picture of drifting buoy with built-in GPS antenna/receiver, position data transmitter/antenna and battery on the buoy bottom. The buoy cover is made by hard type plastic and aluminum. Total weight in air is $5 \mathrm{~kg}$ and the diameter is $30 \mathrm{~cm}$.

A preliminary transmission performance test of the ORBCOMM drifting buoy was conducted at coastal sea in mooring condition. Fig. 7 shows the position error distribution throughout 24 hours observation at that time. The position data were transmitted every 5 minutes. 2DRMS was 31.2 meters and receivable rate of transmitted data was almost $100 \%$ in this observation. The position accuracy is not so good due to the contamination of multi-path from sea surface wave. Fig. 8 shows the training ship Umitaka-Maru's track from Tokyo to Tokyo monitored by ORBCOMM system during a round-Japan cruise in summer 2001. Transmission interval of ship position data was every 6 hours. This correct tracking performance suggests that the system might work effectively for a ship's crisis management measure against the pirate

\section{DISCUSSION}

GPS position itself is very important in safety cruise and fisheries, but as some cases like GPS compass and ORBCOM GPS buoy were introduced, new and unique applications for fishery area using GPS will be developed more and more in the future.

\section{ACKOWLEDGEMENTS}

I would like to express my deep gratitude for training ship Umitaka-Maru's crews and staff of Zeniraito-Buoy Co. Ltd. who helped and advised me at the experiments. This study was conducted in 2001 as a part of grant-in-aid for scientific research (project No.12660165, (C)(2)) of Ministry of Education, Culture, Sports, Science and Technology. 